\title{
The greatest challenge to 21st century paleontology: When commercialization of fossils threatens the science
}

\author{
Kenshu Shimada, Philip J. Currie, Eric Scott, and Stuart S. Sumida
}

As we proceed into the 21st century, the science of paleontology has achieved a remarkable prominence and popularity, providing increasingly detailed perspective on critical biological and geological processes. Spectacular new discoveries excite the imagination and spur new investigations, while more abundant fossils studied using new techniques enable more precise interpretations of diversity, variation, changes through time, and responses to geological and climatic factors. Paleontology presently enjoys a new "Golden Age," progressing by leaps while also serving, as always, to inspire young minds to explore science and the natural world.

Yet at the outset of the millennium, three interconnected, troubling challenges confront paleontologists: 1) a shrinking job market, 2) diminishing funding sources, and 3 ) heightened commercial-

Editor's note: The commercial collection and sale of fossils, as well as the still developing regulations involving collection of fossils on public lands, have emerged as one of the most contentious issues in paleontology. These issues pit not only professional paleontologists and commercial collectors against each other, but have produced rifts within the paleontological community. Here Shimada and his co-authors vigorously present a position supported by many vertebrate paleontologists. I repeat a call in an earlier commentary (Plotnick, 2011; palaeo-electronica.org/2011_1/commentary/mainstream.htm) for additional contributions that would discuss these issues that are so crucial to our field. Please send directly to Roy E. Plotnick (plotnick@uic.edu)

Kenshu Shimada. Department of Environmental Science and Studies and Department of Biological Sciences, DePaul University, Chicago, Illinois 60614, USA; Sternberg Museum of Natural History, Fort Hays State University, Hays, Kansas 67601, USA. kshimada@depaul.edu

Philip J. Currie. Department of Biological Sciences, University of Alberta, Edmonton, Alberta T6G 2E9, Canada. philip.currie@ualberta.ca

Eric Scott. Division of Geological Sciences, San Bernardino County Museum, Redlands, California 92374, USA. escott@sbcm.sbcounty.gov

and Department of Biology, California State University at San Bernardino, San Bernardino, California 92407, USA

Stuart S. Sumida. Department of Biology, California State University at San Bernardino, San Bernardino, California 92407, USA.ssumida@csusb.edu

Shimada, Kenshu, Currie, Philip J., Scott, Eric, and Sumida, Stuart S. 2014. The greatest challenge to 21st century paleontology: When commercialization of fossils threatens the science. Palaeontologia Electronica Vol. 17, Issue 1; $1 \mathrm{E}: 4 \mathrm{p}$; 
ization of fossils. The first two issues are all too familiar to the majority of paleontologists, but they have been common chronic problems in practically all natural science disciplines. The third challenge, commercialization of fossils, is a major developing problem in paleontology that has reached a heretofore unprecedented level of public visibility and debate in this field (e.g., Pringle, 2014). Whereas so much misinformation still pervades public perception of the matter, it is alarming that this issue appears to have not been fully recognized as a serious threat to the science of paleontology by the majority of paleontologists.

If one desires to purchase petrified wood, trilobites, fossil shark teeth, or even dinosaur bones, it is not difficult to find commercial suppliers. Many traditional rock shops carry such items. However, sales of fossils have exploded in recent years largely by means of the Internet, with commercial fossil dealers creating an enterprise where the selling and buying of fossils take place openly online. Another growing trend is high profile public auctions, where it is not uncommon to witness spectacular fossils-including complete dinosaur skeletons-being sold to the highest bidders. The new owners are rarely museums or other academic institutions. The extent of commercial trading of fossils is difficult to decipher because it is further complicated by the black market, where illegally collected, exported, and/or imported fossils are traded unnoticed by professional paleontologists.

Three specific recent episodes exemplify the commercialization issue. In the spring of 2012, a skeleton of Tarbosaurus (a Tyrannosaurus relative) that was illegally collected in and smuggled out of Mongolia appeared at an auction for sale in the U.S. (Williams, 2013). In the spring of 2013, a bill ("HB 392") that proposed to allow sales of fossils from Makoshika State Park in Glendive, Montana, was passed by the Montana House of Representatives for consideration by the State Senate. Then, in the fall of 2013, a major natural history museum in California put up multiple fossils for auction (Pringle, 2014). However, diligent efforts by a number of vertebrate paleontologists resulted in repatriation of the Tarbosaurus to Mongolia, successful blocking of the Montana bill, and a complete withdrawal of fossils from the auction by the California museum.

What was at stake in all three cases was the loss of scientifically significant fossils from the public domain. Fossil commercialism is a matter that not only concerns vertebrate paleontologists, but rather all paleontologists. For any scientific study, the ability to reproduce data is a basic prerequisite. In paleontology, the fossils themselves carry, or often are, the data. Reproducibility of paleontological data is permitted only through permanency and accessibility of all examined fossils in stable repositories under public trust. Fossils outside of the public domain, such as those in private collections, do not meet these essential standards. It is for this reason that virtually all high-level scientific journals do not publish data obtained from privately-owned specimens.

The three highlighted cases also reflect a larger issue that has become deeply entrenchedthe public perception that "It's okay to sell and buy fossils." The vast majority of the general population are unaware that the commercialization of fossils is even a problem, based upon our experience through teaching and various outreach programs. In fact, there are even people who erroneously perceive that commercial fossil collecting is equivalent to paleontology. This matters to all areas of paleontology because the general population also includes lawmakers and top administrators in academic institutions (as demonstrated by the state park and museum cases). When decision makers lack a proper understanding of the nature of paleontological research (e.g., when they are duped into thinking that the monetary value of fossils outweighs their scientific value), all paleontological science suffers because such misguided perceptions then also contribute to a further decline in collections-based research. This in turn severely affects decisions about research funding, employment, and job security in academic institutions.

Whether or not it's okay to sell and buy fossils is a matter of debate on scientific and ethical grounds, with analytical rigor and professional honesty squaring off against free enterprise. Within science, the integrity of the data trumps other concerns such as monetary value; this is both a practical consideration and an ethical one. It is for this reason that the bylaws of the Society of Vertebrate Paleontology (SVP) state explicitly: "The barter, sale, or purchase of scientifically significant vertebrate fossils is not condoned, unless it brings them into, or keeps them within, a public trust" and adds "Any other trade or commerce in scientifically significant vertebrate fossils is inconsistent with the foregoing, in that it deprives both the public and professionals of important specimens, which are part of our natural heritage." To our knowledge, the SVP's stance is the highest professional standard among all the existing paleontology-based profes- 
sional organizations. It stems from the understanding that the primary value of fossils is their scientific importance, and how they further our understanding of the natural world. Consequently, the commercialization of fossils is fundamentally destructive to the science of paleontology. It is noteworthy that the SVP bylaws provide room for commercial collectors to work cooperatively with academic paleontologists to bring scientifically significant fossils into public trust. To be clear, the SVP bylaws also allow hobby collecting where conducted legally. In fact, academic paleontologists often depend upon fossil collecting by hobbyists and amateur paleontologists particularly because innumerable important scientific discoveries have been made by such people. It is also an important avenue to spark interests of youngsters who may become the next generation of paleontologists!

Paleontologists should not expect the general public to readily recognize and appreciate the scientific significance of fossils, because this significance inherently emerges from the eyes of paleontologists. Even the most common forms of fossils, such as trilobites and shark teeth, may be scientifically significant depending on the investigative questions asked. Whereas new discoveries and new species often command the limelight, it is more commonly abundant fossils that are increasingly enabling more precise conclusions regarding ranges of morphological variation, true diversity of organisms, and evolutionary responses of plants and animals to changing regional and global conditions. In fact, these are the very studies that often have the greatest impact for understanding living organisms and present-day ecosystems.

Based upon this, if a fossil provides useful scientific data, then it is scientifically significant. Therefore, significant fossils require preservation in perpetuity because all data are important, and good scientists must not cherry-pick their data in advance. Choosing to remove scientific data for other than legitimate analysis-based reasons is, at best, unscientific-and at worst, damaging to science itself. Yet commercial sales of fossils are based upon just such cherry-picking. Unusual or rare fossils are targeted by commercial collectors because of their potentially high monetary values, and while those "trophy specimens" may be offered up for scientific scrutiny, other more "common" fossils are usually treated as nothing more than commodities by commercial dealers.

In this environment, commercialization of fossils will likely thrive unless something is done. Yet where such commercialization is conducted legally, paleontologists have no right to ask commercial fossil dealers to stop selling fossils. So, what can paleontologists do? We here recommend strengthening public education on this matter regardless of one's area of specialty-paleobotanists and ichnologists as well as invertebrate and vertebrate paleontologists-that unrestricted commercialization of fossils hurts the science of paleontology. Our experiences suggest that those who didn't know that commercialization of fossils is a problem are generally quite receptive once they learn about the role of repository museums and how the science of paleontology works. Our hope is to challenge the very concept of commercial supply by reducing through public education the demand of fossils. Such an effort should also promote the awareness of the benefits of housing scientifically significant fossils in public institutions.

To change the perception of the general public, a concerted effort by all types of paleontologists and paleontological organizations is needed. First and foremost, paleontologists must lead by example. If the integrity and comprehensiveness of the available data are paramount-and in good science, they must be-then other considerations such as monetary value or free enterprise must be considered secondary. Conversely, where profit and free enterprise are foremost when dealing with fossils, it must be acknowledged that science has been left entirely by the wayside.

Following directly from this reasoning, it becomes incumbent upon scientific societies affiliated with SVP to "respect the data" and follow SVP's established policies for preserving paleontological resources in the public sphere. Simply put, the sales of fossils should not be permitted at meetings of these societies. Given the scientific merit of our arguments, requesting such a course of action is not unreasonable. In addition, local geology and fossil clubs can also be used as agents of change, to help the wider public recognize the scientific importance of fossils and why the scientific value of fossils outweighs any perceived monetary worth. This type of cooperation both serves science and preserves the joy of direct encounters with fossils. Finally, suggestions have also been made that, similar to the annual meetings of the SVP, our paleontological community can perhaps promote the sales of fossil replicas and "paleo arts" (e.g., paintings and 3-D models of extinct organisms) as acceptable alternatives. Working with and educating the public in multiple venues is a more productive avenue for preserving 
fossils than arguing endlessly with commercial collectors and dealers.

The bottom line is that scientists must redouble their efforts to change the perception of the general public about why fossils are significant, and why this significance outweighs mere monetary worth. Where fossils are informative-because they can provide data on systematics, stratigraphy, morphology, function, ontogeny, paleoecology, and so forth-they are significant. The ethics of science dictate that these fossils-as nonrenewable natural resources and hence irreplaceable sources of data-be conserved in perpetuity. In order to avoid the ever-increasing loss of such fossils to commer- cialism, which undermines collections-based scientific research and leads to further cuts in funding and job opportunities, the scientific significance of fossils must be increasingly emphasized. We therefore consider the battle against heightened commercialization of fossils to be the greatest challenge to paleontology of the 21st century.

\section{REFERENCES}

Pringle, H. 2014. Selling America's Fossil Record. Science, 343:364-367.

Williams, P. 2013. Bones of contention: a Florida man's curious trade in Mongolian dinosaurs. New Yorker, (January 28):52-63. 